\title{
Produção e qualidade de forragem da mistura de aveia e azevém sob dois métodos de estabelecimento ${ }^{1}$
}

\section{Marta Gomes da Rocha ${ }^{2}$, Lilian Elgalise Techio Pereira ${ }^{3}$, Luciene Fernanda Barros Scaravelli ${ }^{4}$, Clair Jorge Olivo ${ }^{5}$, Carlos Alberto Agnolin ${ }^{4}$, Magnos Fernando Ziech ${ }^{4}$}

\author{
1 Pesquisa realizada com recursos próprios. Laboratório de Bovinocultura de leite - UFSM \\ 2 Departamento de Zootecnia - UFSM. Pesquisadora CNPq. \\ 3 Graduação em Zootecnia - UFSM. Bolsista CNPq. \\ 4 Graduação em Zootecnia - UFSM. \\ ${ }^{5}$ Departamento de Zootecnia - UFSM.
}

RESUMO - Neste trabalho, comparou-se a sobre-semeadura de aveia (Avena strigosa Schreb.) e azevém (Lolium multiflorum Lam.) em pastagem de coastcross (Cynodon dactylon (L.) Pers.) ao cultivo estreme como métodos de implantação de pastagens de inverno em sistema de pastejo rotacionado com vacas holandesas em lactação. Foram avaliados a produção total de MS (PTF), a massa de forragem de entrada (MFE), o resíduo (RES), as perdas de forragem (PD), a taxa de acúmulo diário de MS (TAD), a carga animal (CA), a oferta de forragem (OF) e a biomassa de lâminas foliares (BLF). Para determinação da composição botânica, foram separados em cada espécie (aveia, azevém e coastcross) os componentes estruturais folha, colmo e material senescente. Na entrada e saída dos animais da pastagem, foram colhidas amostras por simulação de pastejo para determinação dos teores de PB e FDN. Não houve diferença entre tratamentos para PTF, MFE, RES,

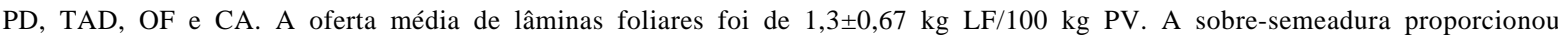
maior biomassa de lâminas foliares disponibilizando forragem com maior teor de PB e menor de FDN na entrada e saída dos animais da pastagem.

Palavras-chave: bovinos leiteiros, coastcross, pastejo rotativo, sobre-semeadura

\section{Forage production and quality of oats and ryegrass mixture under two establishment methods}

\begin{abstract}
The oats (Avena strigosa Schreb.) and ryegrass (Lolium multiflorum Lam.) sodseeding in pasture of coastcross (Cynodon dactylon (L.) Pers.) was compared to oats and ryegrass in extreme tillage, as establishment methods of winter pastures under rotational stocking with lactating Holstein dairy cows. The total DM production (DMP), pre-grazed herbage mass, residue (RES), forage losses (FL), daily DM accumulation rate (DAR), stocking rate (SR), forage on offer (FO) and leaf blade biomass (LBB) were evaluated. For botanical composition, oats, ryegrass and coastcross were separated in the structural components: leaves, stems and dead material. Hand plucking samples for CP and NDF determinations were collected during pre- and post-grazing. The DMP, HM, RES, FL, DAR, SR and FO were not different among treatments. The average leaf blade on offer was $1.3 \pm 0.67 \mathrm{~kg} / 100 \mathrm{~kg} \mathrm{BW}$. The sodseeding showed greater values of LBB resulting in forage with greater $\mathrm{CP}$ and smaller NDF concentration both during pre- and post-grazing.
\end{abstract}

Key Words: coastcross, dairy cattle, rotational stocking, sodseeding

\section{Introdução}

Os sistemas de produção em pastagem são os mais viáveis em propriedades leiteiras com poucos recursos para investimento. A utilização de gramíneas anuais de estação fria como pastagens constitui alternativa de produção de forragem em sistemas de rotação com culturas de verão, visando suprir a deficiência alimentar ocasionada por baixas temperaturas, geadas e pouca luminosidade no outono e inverno (Roso et al., 1999).
No Rio Grande do Sul, as espécies mais utilizadas para pastagens de inverno em sistemas de produção animal são a aveia-preta (Avena strigosa Schreb.) e o azevém (Lolium multiflorum Lam.). A aveia-preta, comparada ao azevém, possui ciclo mais curto e produção de forragem mais precoce. O azevém, por sua vez, é bastante utilizado pela facilidade de ressemeadura natural, pela resistência a doenças, pelo bom potencial de produção de sementes e pela possibilidade de associação a outras espécies (Santos et al., 2002). As associações entre duas ou mais espécies forrageiras com 
produções em períodos distintos seriam uma forma de minimizar o período de carência alimentar. A mistura de aveia preta e azevém visa associar os picos de produção de massa verde das diferentes espécies para evitar a flutuação no fornecimento de forragem aos animais, estendendo, assim, o período de pastejo (Roso et al., 1999).

$\mathrm{Na}$ Região Sul do Brasil, a transição primavera-verão e outono-inverno, quando as forrageiras de uma estação estão encerrando seu desenvolvimento e as seguintes ainda não estão aptas ao pastejo, consiste nos períodos críticos para a alimentação animal em sistemas de produção em pastagens. A carência alimentar nesse período ocasiona quedas na produção leiteira e menor captação de recursos pelo produtor. É comum a utilização de suplementação com silagem, feno ou concentrados nesses períodos (Rocha et al., 2003) para evitar perdas na produção, acarretando, porém, aumento nos custos finais. Assim, a utilização de pastagens ainda é a forma mais econômica de produção de leite também nestes períodos.

As gramíneas perenes de ciclo estival, como as espécies do gênero Cynodon, são bastante utilizadas na produção leiteira por suportar altas cargas animais e permitir longo período de utilização. Dentro desse gênero, destaca-se a coastcross (Cynodon dactylon (L.) Pers.), que permite a sobre-semeadura de espécies forrageiras de clima temperado, como a aveia-preta e o azevém.

A viabilidade da sobre-semeadura está relacionada à influência de uma espécie sobre a produtividade de outra. No manejo de pastagens, devem ser considerados fatores que assegurem seu pleno estabelecimento e sua persistência, assegurando rendimento e qualidade para a utilização mais eficiente pelos animais (Lenzi, 2003).

A sobre-semeadura de aveia e azevém em pastagens perenes de estação quente consiste em uma alternativa de ajuste no fornecimento de forragem, pois permite a ocupação das áreas durante todo o ano, tornando mais eficiente a utilização de pastagens. Este trabalho foi realizado com o objetivo de avaliar dois métodos de estabelecimento da mistura de aveia e azevém sobre a produção e qualidade da pastagem de inverno em sistema de pastejo rotacionado para produção de leite.

\section{Material e Métodos}

O trabalho foi conduzido no período de junho a outubro de 2004, em área localizada na região fisiográfica denominada Depressão Central do Rio Grande do Sul, com altitude de 95 m, latitude $29^{\circ} 43^{\prime}$ Sul e longitude $53^{\circ} 42$ Oeste. A temperatura e a precipitação média do período experimental, conforme dados da Estação Experimental Meteorológica da Universidade Federal de Santa Maria - UFSM, localizada próximo à área experimental, foram de $16,6^{\circ} \mathrm{C}$ e $89,7 \mathrm{~mm}$, respectivamente (Figura 1).

O solo da área experimental é classificado como Argissolo Vermelho Distrófico Arênico e pertence à unidade de mapeamento São Pedro (EMBRAPA, 1999). O clima da região é Cfa (subtropical úmido), conforme classificação de Köppen. A análise de solo apresentou os seguintes valores médios: $\mathrm{pH}-\mathrm{H}_{2} \mathrm{O}: 5,2$; Índice SMP: 5,6; $22 \%$ de argila m/V; P: $15,4 \mathrm{mg} / \mathrm{L} ; \mathrm{K}: 43 \mathrm{mg} / \mathrm{L} ; 3,3 \% \mathrm{MO}$ m/V; Al: 1,0 cmolc/L; Ca: 3,6 cmolc/L; Mg:1,6 cmolc/L; 50\% de saturação de bases e $16 \%$ de saturação por alumínio.

A área experimental ( $1,2 \mathrm{ha}$ ) foi subdividida em cinco piquetes de aproximadamente $0,25 \mathrm{ha}$, sendo um piquete utilizado para adaptação dos animais.

Os tratamentos testados foram: $\mathrm{Av}+\mathrm{Az}$ - pastagem de aveia (Avena strigosa Schreb) e azevém (Lolium multiflorum Lam.) em cultivo estreme; e Av+Az+B - pastagem de aveia e azevém sobre-semeada em coastcross (Cynodon dactylon (L.) Pers.).

A pastagem de coastcross já havia sido implantada manualmente em março de 2003, por meio de mudas obtidas pela subdivisão de touceiras. Nesta ocasião, foram aplicados $12 \mathrm{~m}^{3} /$ ha de chorume bovino. Em 15 de abril de 2004, a pastagem de aveia e azevém foi estabelecida por sobresemeadura na área de coastcross (as sementes foram distribuídas a lanço e, em seguida, incorporadas por meio de gradagem leve). $\mathrm{Na}$ área cultivada exclusivamente com espécies de inverno, foi feito preparo mínimo do solo, com duas gradagens. Foram utilizados $80 \mathrm{~kg} / \mathrm{ha}$ de semente de aveia preta e $40 \mathrm{~kg} / \mathrm{ha}$ de semente de azevém, previamente

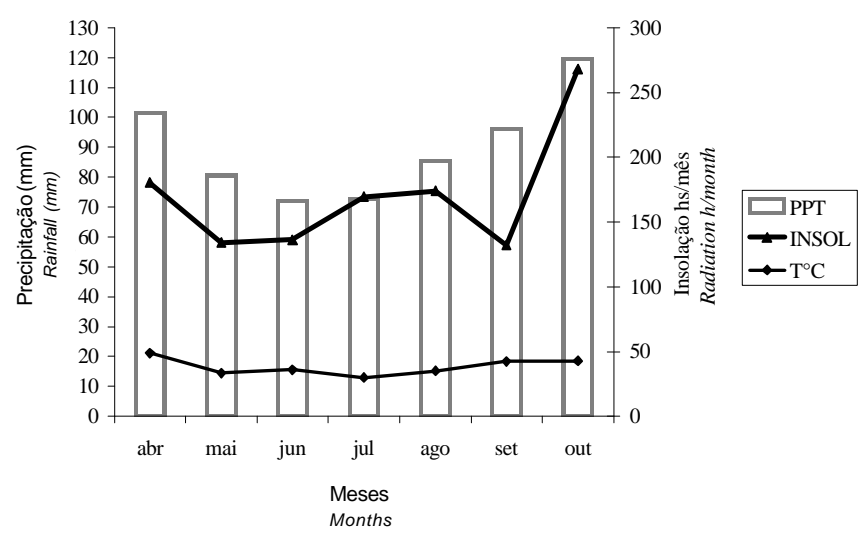

Figura 1 - Dados médios mensais de precipitação (PPT, mm), temperatura $\left(\mathrm{T}^{\circ} \mathrm{C}\right)$ e insolação (INSOL, hs/mês) no período de abril a outubro de 2004

Figure 1 - Rainfall, temperature and radiation, monthly average data from April to October of 2004. 
misturados, corrigidos para 100\% de germinação. A adubação consistiu da aplicação de $200 \mathrm{~kg} / \mathrm{ha}$ de N-P-K da fórmula 05-20-20 na ocasião do plantio e de $100 \mathrm{~kg} / \mathrm{ha}$ de nitrogênio em cobertura, na forma de uréia, divididos em cinco aplicações, realizadas após cada pastejo.

$\mathrm{O}$ método de pastejo foi rotativo, adotando-se como critério de entrada dos animais na pastagem a existência de 1.400 a $2.000 \mathrm{~kg} / \mathrm{ha}$ de MS de massa de forragem (MF). A carga animal foi calculada para um consumo de $50 \%$ da MF inicial, em dois dias de utilização, adotando-se um valor de 4,5\% do PV como taxa de desaparecimento. Foram utilizadas vacas holandesas em lactação (peso médio de $500 \mathrm{~kg}$ ) durante um período de pastejo de 06/06 a 13/10. Em cada tratamento, foram realizados cinco pastejos, correspondendo aos dias 09-10/06, 07-08/07, 10-11/08, 12-13/09 e 13-14/10 em $\mathrm{Av}+\mathrm{Az}+\mathrm{B}$ e em $\mathrm{Av}+\mathrm{Az}$ nos dias 22-23/06, 14-15/07, 17-18/08, 18-19/09 e 13-14/10, de modo que os dias de descanso das pastagens corresponderam aos intervalos de pastejo.

A MF foi avaliada antes e depois de cada pastejo, por meio da técnica de dupla amostragem (Wilm, 1944), com cinco cortes e 15 estimativas visuais por repetição. A forragem proveniente das amostras cortadas foi homogeneizada e duas amostra foram retirada para estimativa da composição botânica da pastagem e outra para determinação do teor de MS. Na amostra para determinação da composição botânica, cada espécie (aveia, azevém e coastcross) foi separada nos componentes estruturais folha, colmo e material senescente. As amostras foram secas em estufa de ventilação forçada a $65^{\circ} \mathrm{C}$ para estimativa do percentual de cada componente, com base na MS.

A estimativa da taxa de acúmulo diário de MS (TAD, em $\mathrm{kg} / \mathrm{ha} / \mathrm{dia}$ ) foi feita a cada 28 dias utilizando-se duas gaiolas de exclusão ao pastejo por unidade experimental. Cada amostra foi obtida de uma área de $0,25 \mathrm{~m}^{2}$. A taxa de acúmulo de MS do período foi estimada por meio da equação descrita por Campbell (1966).

A produção total de MS foi calculada pelo somatório das produções dos períodos (taxa de acúmulo diário $\times$ número de dias do período) mais a massa de forragem inicial. A estimativa do percentual de produção de MS dos componentes estruturais das espécies da pastagem foi obtida dividindo-se a produção em cada período pela produção total de MS do período e multiplicando o resultado por 100.

Os teores de PB e FDN da forragem aparentemente consumida pelos animais foram determinados por meio de análise laboratorial de amostras colhidas via simulação de pastejo (Euclides et al., 1992) na entrada e saída dos animais da pastagem, realizada por dois observadores treinados. As amostras colhidas foram pesadas e secas em estufa de ventilação forçada a $65^{\circ} \mathrm{C}$ e trituradas em moinho tipo Willey.

Para determinar as perdas de forragem (PD), em data anterior ao início do experimento, foram marcados e identificados por estacas quatro pontos amostrais em cada unidade experimental e, em área delimitada por um quadrado de $0,02 \mathrm{~m}^{2}$, em cada um dos pontos, foi removido todo o material morto encontrado junto ao solo. A cada 28 dias, em cada ponto amostral, foram coletados a forragem danificada pelo pisoteio e pelo pastejo e o material morto. As amostras recolhidas foram secas em estufa de ventilação forçada a $65^{\circ} \mathrm{C}$ e pesadas em balança de precisão após 72 horas.

O desaparecimento de forragem (DF) foi calculado, em cada pastejo, pela fórmula: $\mathrm{DF}=[\mathrm{MFE}-(\mathrm{RES}+\mathrm{PD})], \mathrm{em}$ que MFE é a massa de forragem na entrada dos animais; RES a massa de forragem na saída dos animais; e PD, as perdas de forragem do período correspondente ao período de pastejo. A oferta de forragem, em kg MS/100 kg PV, foi determinada pela fórmula: $\mathrm{OF}=(\mathrm{MFE}+\mathrm{TAD}) / \mathrm{CA}$, em que OF é a oferta de forragem; TAD, a taxa de acúmulo diária de MS; e CA, a carga animal.

O delineamento experimental foi completamente casualizado, com duas repetições de área e em parcelas subdivididas no tempo. Os resultados foram submetidos à análise de variância e, quando detectadas diferenças, as médias foram comparadas pelo teste Tukey a $5 \%$ de significância. As variáveis que apresentaram interação $T * P$ foram submetidas ao teste de regressão polinomial até terceira ordem, a 5\%, utilizando-se o pacote estatístico SAS versão 6.12 (SAS, 1997). A informação de composição botânica da pastagem foi analisada por meio do pacote estatístico MULTIV (Pilar, 1997). O modelo matemático geral referente à análise das variáveis estudadas é representado por:

$$
\mathrm{Y}_{\mathrm{ij}}=\mu+\mathrm{T}_{\mathrm{i}}+\mathrm{P}_{\mathrm{j}}+\mathrm{T}_{\mathrm{i}} \mathrm{P}_{\mathrm{j}}+\varepsilon_{\mathrm{ij}}
$$

em que: $\mathrm{Y}_{\mathrm{ij}}=$ variáveis dependentes; $\mu=$ média de todas as observações; $\mathrm{T}_{\mathrm{i}}=\mathrm{i}$-ésimo tratamento; $\mathrm{P}_{\mathrm{j}}=\mathrm{j}$-ésimo período; $\mathrm{T}_{\mathrm{i}} \mathrm{P}_{\mathrm{j}}=$ interação i-ésimo tratamento $\times \mathrm{j}$-ésimo período; e $\varepsilon_{\mathrm{ij}}=$ erro experimental residual.

\section{Resultados e Discussão}

A massa de forragem no início do pastejo permitiu manter a carga animal com valores semelhantes para os dois métodos de estabelecimento ( $\mathrm{P}>0,05)$, o que pode ser comprovado pelo resíduo de forragem dos tratamentos, que não foram diferentes $(\mathrm{P}>0,05)$ (Tabela 1$)$.

A massa de forragem de entrada média foi de $1.802 \pm 277,4 \mathrm{~kg} / \mathrm{ha}$ de MS. A disponibilidade média, consi- 
Tabela 1 - Massa de forragem ( $\mathrm{kg} / \mathrm{ha}$ de MS), resíduo ( $\mathrm{kg} / \mathrm{ha} \mathrm{MS),} \mathrm{carga} \mathrm{animal} \mathrm{(kg/ha} \mathrm{PV),} \mathrm{taxa} \mathrm{de} \mathrm{acúmulo} \mathrm{diário} \mathrm{de} \mathrm{MS} \mathrm{(kg/ha/dia} \mathrm{de}$ $\mathrm{MS}$ ), produção de forragem ( $\mathrm{kg} / \mathrm{ha}$ de MS), oferta de forragem (OF, $\mathrm{kg} \mathrm{MS} / 100 \mathrm{~kg} P V$ ) e biomassa de lâminas foliares (BLF, $\mathrm{kg} / \mathrm{ha} \mathrm{MS}$ ) em pastagem de aveia (A. strigosa) e azevém ( $L$. multiflorum) estabelecidas por sobre-semeadura ou em cultivo estreme

Table 1 - Herbage mass ( $\mathrm{kg} / \mathrm{ha} D M)$, residual herbage mass ( $\mathrm{kg} / \mathrm{ha} \mathrm{DM})$, in $\mathrm{kg} / \mathrm{ha}$ of dry matter (DM), stocking rate ( $\mathrm{kg} B W / \mathrm{ha})$, daily DM accumulation rate ( $\mathrm{kg} D \mathrm{M} / \mathrm{ha} /$ day), total DM production ( $\mathrm{kg} \mathrm{DM} / \mathrm{ha}$ ), forage on offer ( $F O, \mathrm{~kg} D M / 100 \mathrm{~kg} \mathrm{BW}$ ) and leaf blade biomass ( $\mathrm{kg} D M / \mathrm{ha}$ ) of oats (A. strigosa Schreb.) and ryegrass (L. multiflorum Lam.) pasture established for sodseeding or in extreme tillage

\begin{tabular}{|c|c|c|c|}
\hline & $\begin{array}{l}\text { Sobre-semeadura } \\
\quad \text { Sodseeding }\end{array}$ & $\begin{array}{c}\text { Cultivo estreme } \\
\text { Extreme tillage }\end{array}$ & $\begin{array}{c}\text { Significância } \\
\text { Significance }\end{array}$ \\
\hline Massa de forragem ${ }^{1}$ (Herbage mass) & $1.837,7$ & $1.765,7$ & n.s* \\
\hline Residuo (Residual herbage mass) & $1.045,5$ & $1.095,1$ & n.s \\
\hline Carga animal (Stocking rate) & 934,6 & $1.011,9$ & n.s \\
\hline Taxa de acúmulo diário de MS (Daily DM accumulation rate) & 65,0 & 68,0 & n.s \\
\hline Produção total de forragem (Total DM production) & $7.343,2$ & $7.545,0$ & n.s \\
\hline Oferta de forragem ${ }^{1}$ (Forage on offer) & 9,3 & 9,8 & n.s \\
\hline Biomassa de lâminas foliares ${ }^{1}$ (Leaf blade biomass) & 938,1 & 736,8 & $\mathrm{P}<0,05$ \\
\hline
\end{tabular}

* n.s: médias não-significativas $(P>0,05)$.

${ }^{*}$ n.s.: not significant averages $(P>0.05)$.

${ }^{1}$ MFE: $=1.498+18.09 X-0.157 X^{2} ; P<0.01 ; R^{2}=0.47 ;$ OF: $\hat{Y}=10,8-0,08 X+0,00072 X^{2} ; P=0,01 ; R^{2}=0,32 ; B L F: \hat{Y}=1084,78-4,87 X ; P<0.01 ; R^{2}=0,37$.

derando a massa de forragem de entrada e resíduo, foi de $1.441,6$ e $1.430,46 \mathrm{~kg} / \mathrm{ha}$ de MS em pastagem sobre-semeada ou cultivo estreme, respectivamente. O resíduo pós-pastejo foi de $1.070 \pm 329 \mathrm{~kg} /$ ha de MS. Nestas condições, o método de estabelecimento não interferiu na taxa de acúmulo diário de forragem e, conseqüentemente, na produção total de MS da pastagem $(\mathrm{P}>0,05)$, promovendo ofertas de forragem e cargas animais semelhantes $(\mathrm{P}>0,05)$ (Tabela 1$)$. A OF média foi de 9,54 kg MS/100 kg PV. As médias de biomassa de lâminas foliares foram diferentes entre os métodos de estabelecimento $(\mathrm{P}<0,05)$ e corresponderam a $938,1 \mathrm{~kg} / \mathrm{ha}$ MS em sobre-semeadura e a $736,8 \mathrm{~kg} / \mathrm{ha}$ MS para pastagem em cultivo exclusivo.

O momento ideal para a entrada dos animais nos piquetes sob sistema de pastejo rotativo é quando a pastagem apresenta em torno de $1.500 \mathrm{~kg} / \mathrm{ha}$ de MS (Melo, 2000). A adoção de um valor rígido de massa de forragem para entrada dos animais nos piquetes é dificultada pelo cálculo do teor de MS da pastagem a ser estimado na amostragem, pela variação da taxa de acúmulo diário de MS (TAD) e pelos fatores climáticos (precipitação, insolação, temperatura). Assim, foi possível obter, sem prejuízos para a recuperação da pastagem, uma certa amplitude de valores, próximos ao indicado. A faixa ideal de disponibilidade de forragem requerida para o máximo desempenho animal em espécies temperadas situa-se entre 1.200 a $1.600 \mathrm{~kg} / \mathrm{ha}$ de MS (Rocha et al., 2003; Silva et al., 2004).

Os valores de resíduo mantiveram-se dentro do planejado para o experimento, com uma taxa de desaparecimento de $50 \%$ da massa de forragem de entrada. Estes dados confirmam que a determinação da carga animal por meio da taxa de desaparecimento de 4,5\% do PV (consumo e perdas de forragem) é adequada a este método de pastejo.
A carga animal média encontrada neste trabalho foi considerada satisfatória para a utilização de $100 \mathrm{~kg} / \mathrm{ha}$ de nitrogênio $(\mathrm{N})$ na pastagem, pois cargas animais semelhantes foram obtidas com $150 \mathrm{~kg} / \mathrm{ha}$ de $\mathrm{N}$ (Rocha et al., 2003 ) e $90 \mathrm{~kg} / \mathrm{ha}$ de $\mathrm{N}$ em cobertura (Frizzo et al., 2003) em pastagens de aveia e azevém.

As taxas de acúmulo semelhantes entre métodos de estabelecimento demonstram que a coastcross não competiu com as espécies sobre-semeadas. Os valores encontrados foram superiores às taxas de acúmulo encontradas em outros experimentos para as mesmas espécies (Frizzo et al., 2003; Roso et al., 1999). Valores inferiores de taxa de acúmulo de forragem também foram obtidos com a utilização de $300 \mathrm{~kg} / \mathrm{h}$ a de N (Rocha et al., 2004), valor três vezes superior ao utilizado neste trabalho. Os valores de taxa de acúmulo foram superiores aos encontrados por Roso et al. (2000), ao avaliarem misturas de espécies forrageiras de clima temperado. As médias foram superiores ainda às obtidas em trabalhos utilizando o sistema contínuo como método de pastejo, com ofertas de forragem semelhantes (Rocha et al., 2004; Freitas et al., 2005; Frizzo et al., 2003), o que pode ser explicado, provavelmente, pelo valor do resíduo pós-pastejo, pois, conforme Rodrigues \& Reis (1999), a recuperação das plantas após a desfolha é influenciada pela área foliar remanescente após o pastejo, o que, associado às condições climáticas favoráveis de temperatura, precipitação e insolação (Figura 1), possibilitou máxima taxa de acúmulo diário de forragem. As médias mensais de temperatura, precipitação e insolação foram consideradas normais, pois estiveram de acordo com a média dos últimos 30 anos.

O comportamento das plantas forrageiras de clima temperado em pastagens com espécies de clima tropical, 
segundo Gerdes et al. (2005), é resultado da interação potencial genético $\times$ meio ambiente. A produção total de forragem é um importante fator para avaliação da viabilidade da sobre-semeadura, pois está diretamente relacionada ao manejo da pastagem. Neste sentido, a sobre-semeadura demonstrou ser alternativa, durante o inverno, para a utilização das áreas ocupadas com Cynodon, proporcionando produção de forragem semelhante ao cultivo estreme.

A adequação de carga usando taxa de desaparecimento de $4,5 \%$ do PV permitiu que oferta de forragem não fosse limitante. Segundo Freitas et al. (2005), a massa de forragem e a oferta possuem efeitos diretos no consumo de MS pelos ruminantes em pastejo. A oferta de forragem não limitante é aquela que disponibiliza ao animal em pastejo aproximadamente três vezes o consumo estimado de MS em forrageiras temperadas.

Os valores observados para biomassa de lâminas foliares não foram considerados limitantes para o desempenho animal. Silva et al. (2004) obtiveram melhores resultados econômicos, com valores de $600 \mathrm{~kg} / \mathrm{h}$ a de MS de lâminas foliares para animais em pastagem de aveia e azevém sob pastejo contínuo.

As perdas de forragem foram influenciadas pela interação método de estabelecimento $\times$ período $(\mathrm{P}<0,05)$ (Figura 2). A equação de regressão foi significativa para $\mathrm{Av}+\mathrm{Az}$, com melhor ajuste do modelo quadrático, não havendo ajuste significativo em $\mathrm{Av}+\mathrm{Az}+\mathrm{B}$. O valor médio de perdas de forragem foi de $20 \mathrm{~kg} / \mathrm{ha}$ de $\mathrm{MS}$.

Os maiores valores de perdas de forragem verificados no final do período de utilização em cultivo estreme estão

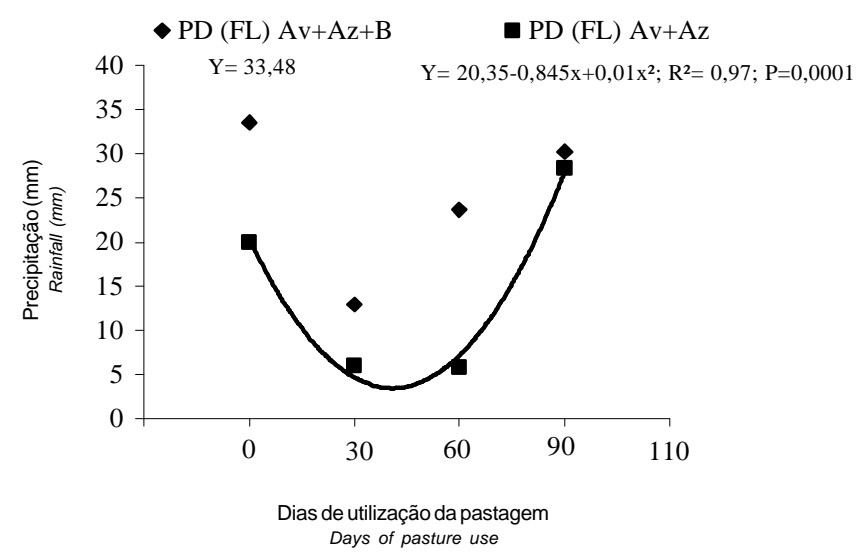

Figura 2 - Perdas de forragem (PD, $\mathrm{kg} / \mathrm{ha}$ de MS) em pastagem de aveia ( $A$. strigosa Schreb.) e azevém (L. multiflorum Lam.) estabelecidas por sobre-semeadura $(A v+A z+B)$ ou em cultivo estreme $(A v+A z)$.

Figure 2 - Forage losses (FL, $\mathrm{kg} / \mathrm{ha}$ of DM) of oats (A. strigosa Schreb.) and ryegrass (L. multiflorum Lam.) pasture established for sodseeding $(A v+A z+B)$ or in extreme tillage $(A v+A z)$. relacionados ao final do ciclo das espécies da pastagem (Rocha et al., 2004). Na sobre-semeadura, as perdas são conseqüência, principalmente, dos danos físicos decorrentes do pisoteio nos estolões da coastcross e, conforme Penati (2002), podem ser influenciadas pela taxa de senescência, pela redução no valor nutritivo, pelos danos físicos decorrentes da queda de forragem durante os processos de escolha, apreensão e manipulação do alimento pelo animal em pastejo. Segundo Frizzo et al. (2003), é importante o conhecimento da quantidade de forragem que é perdida para posteriormente ser reciclada no solo, pois essa quantidade indica que, mesmo em um ambiente diferenciado pela presença da coastcross, a aveia e o azevém possuem grande adaptação ao pastejo e à estrutura da pastagem proporcionada pela sobre-semeadura.

Na Figura 3 são apresentadas em um diagrama de ordenação as variáveis da composição botânica (CB) e dos componentes estruturais da pastagem de aveia + azevém de acordo com os períodos de utilização da pastagem. O agrupamento dos componentes botânicos e estruturais da pastagem representa a correlação entre a contribuição destes componentes e os eixos I e II. Foram consideradas as correlações superiores a 0,5 . O eixo I sintetizou $66 \%$ e o eixo II, 18\% da variação dos componentes botânicos da pastagem. De acordo com o diagrama de ordenação, os componentes lâmina de aveia (LAV), colmo de aveia (CAV), lâmina de azevém (LAZ), colmo de azevém (CAZ), material morto (MM), outras espécies (OSP), lâmina da coastcross (LB) e colmo da coastcross (CB) apresentaram os respectivos valores de correlação com o eixo I: - 0,$80 ;-0,66$; 0,$12 ; 0,96 ; 0,17 ; 0,15 ;-0,40$ e $0,14 \%$. As correlações destes componentes com o eixo II foram de 0,$39 ;-0,72 ; 0,62 ;-0,08$; $-0,32 ; 0,31 ;-0,46$ e $-0,44 \%$, respectivamente.

Conforme o diagrama, a aveia concentrou sua produção de forragem no primeiro e no segundo períodos de pastejo. O componente CAV foi maior no primeiro período, com decréscimo acentuado no pastejo seguinte. Houve redução no percentual de participação das lâminas foliares da aveia na massa de forragem no segundo período. A LAZ apresentou participação significativa a partir do terceiro pastejo. Foi verificado comportamento distinto entre métodos de estabelecimento para CAZ a partir de 08/08. O tratamento de sobre-semeadura permitiu a manutenção de níveis mais elevados de LAZ até o quarto período (setembro), enquanto, em cultivo estreme, houve aumento acentuado de CAZ em detrimento à LAZ. De acordo com as médias de contribuição de cada espécie, a aveia teve menor participação na disponibilidade total de forragem quando a pastagem foi estabelecida por sobre-semeadura. A participação média da 


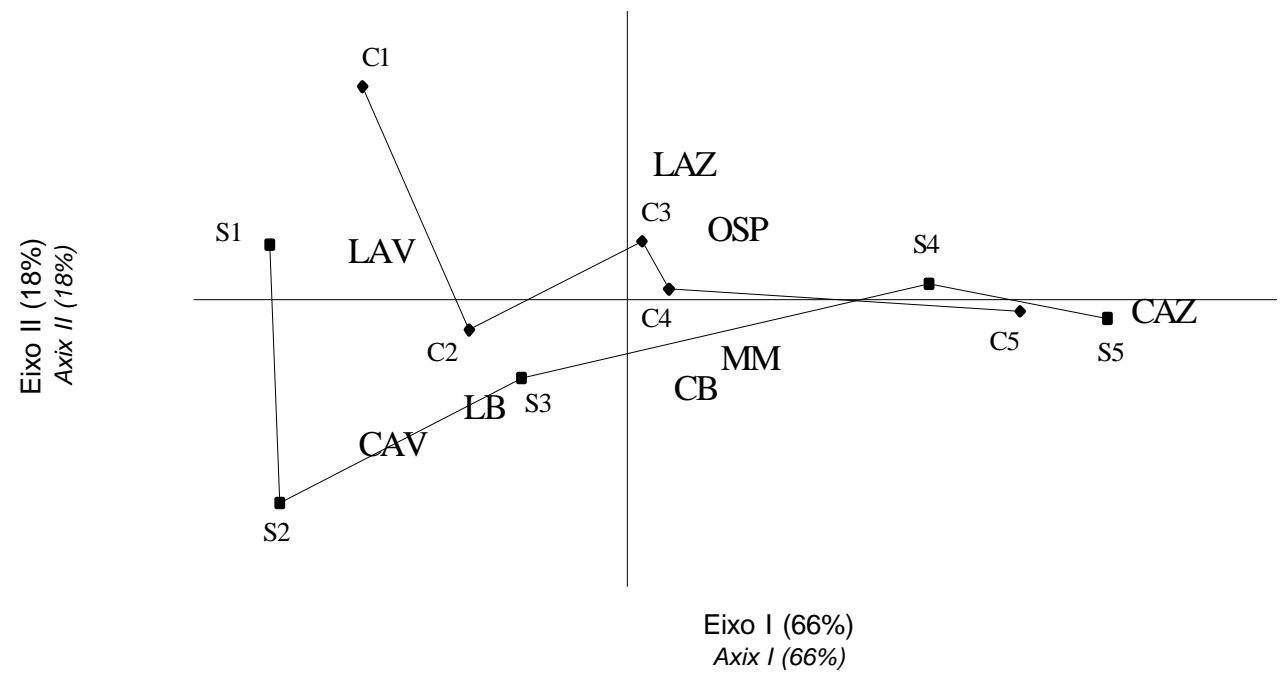

Figura 3 - Diagrama de ordenação dos componentes botânicos e estruturais de aveia ( $A$. strigosa Schreb.) e azevém ( $L$. multiflorum Lam.) sob dois métodos de estabelecimento durante os períodos de pastejo: sobre-semeadura de aveia e azevém em coastcross $(\mathrm{S} 1=09 / 06 ; \mathrm{S} 2=07 / 07 ; \mathrm{S} 3=10 / 08 ; \mathrm{S} 4=12 / 09 ; \mathrm{S} 5=13 / 10)$ ou cultivo estreme $(\mathrm{C} 1=22 / 06 ; \mathrm{C} 2=14 / 07$; $\mathrm{C} 3$ = 17/08; $C 4=18 / 09 ; \mathrm{C} 5=13 / 10)$. Valores de correlação com o eixo I, de lâmina de aveia (LAV), colmo de aveia (CAV), lâmina de azevém (LAZ), colmo de azevém (CAZ), lâmina de coastcross (LB), colmo de coastcross (CB), material morto (MM) e outras espécies $(\mathrm{OSP})$ : $\mathrm{LAV}=-0.80 ; \mathrm{CAV}=-0.66 ; \mathrm{LAZ}=0.12 ; \mathrm{CAZ}=0.96 ; \mathrm{MM}=0.17 ; \mathrm{OSP}=0.15 ; \mathrm{LB}=-0,40 ; \mathrm{CB}=0,14$. Valores de correlação com o eixo II : $\mathrm{LAV}=0.39 ; \mathrm{CAV}=-0.72 ; \mathrm{LAZ}=0.62 ; \mathrm{CAZ}=-0.08 ; \mathrm{MM}=-0.32 ; \mathrm{OSP}=0.31 ; \mathrm{LB}=-0,46$; $\mathrm{CB}=-0,44$.

Figure 3 - Diagram of ordenation of botanical and structural components of oats (A. strigosa Schreb.) and ryegrass (L. multiflorum Lam.) pasture under two establishment methods, during the grazing periods: sodseeding of oats and ryegrass at coastcross $(S 1=09 / 06 ; S 2=07 / 07 ; S 3=10 / 08 ; S 4=$ 12/09; $S 5=13 / 10)$ and extreme tillage $(C 1=22 / 06 ; C 2=14 / 07 ; C 3=17 / 08 ; C 4=18 / 09 ; C 5=13 / 10)$. Values of the correlations with axis $I$, of oats leaf ( $L O)$, oats stem (SO), ryegrass leaf ( $L R Y)$, ryegrass stem (SRY), coastcross leaf ( $L C)$, coastcross stem (SC), dead material (MM) and other species $(O S P): L O=-0.80 ; S T=-0.66 ; L R Y=0.12 ; S R Y=0.96 ; M M=0.17 ; O S P=0.15 ; L C=-0.40 ; S C=0,14$. Values of the correlations with axis II: $L O=0.39 ; S O=-0.72 ; L R Y=0.62 ; S R Y=-0.08 ; M M=-0.32 ; O S P=0.31 ; L C=-0,46 ; S C=-0,44$.

aveia na pastagem sobre-semeada foi de $19 \%$, a do azevém $47,6 \%$ e a da coastcross $24 \%$. Na pastagem em cultivo singular, a aveia foi responsável por $36,7 \%$ da produção total de forragem, enquanto o azevém contribuiu com $50,7 \%$. Os resultados comprovaram que a presença da coastcross afeta a produção total de forragem da aveia, não havendo efeitos sobre o azevém. A produção da coastcross, entretanto, complementa a menor disponibilidade da aveia, proporcionando produções de forragem semelhantes entre métodos de estabelecimento (Tabela 1). As variáveis MM e OSP apresentaram tendência semelhante entre métodos de estabelecimento, não existindo vantagens na presença da coastcross para impedir o desenvolvimento de espécies não desejáveis. Observou-se a participação da coastcross em todas as avaliações quando a aveia e o azevém foram estabelecidos por sobre-semeadura, com valores de até 24,9\% da MFE. Prohmann et al. (2004) também demonstraram que a coastcross apresenta bons valores de disponibilidade antes da queda da temperatura e no final da primavera, quando as condições climáticas favorecem o rebrote da espécie. A essa participação atribui-se a maior biomassa de lâminas foliares quando a aveia e o azevém foram estabelecidos por sobre-semeadura (Tabela 1). As lâminas foliares são o principal componente selecionado pelo animal em pastejo e, na adoção de qualquer manejo, deve-se considerar a contribuição destas lâminas na forragem disponível ao animal.

A concentração da produção de forragem da aveia no início do período de utilização da pastagem confirma a afirmação de Santos et al. (2002) de que a aveia é uma espécie mais precoce que a maioria dos cereais de inverno. Considerando esse comportamento, atribui-se a menor participação na disponibilidade de forragem da aveia quando a pastagem foi estabelecida por sobre-semeadura à competição com a coastcross no início do período de utilização da pastagem. Além disso, a redução do percentual de participação das lâminas foliares da aveia no segundo período foi atribuída ao comportamento seletivo dos animais, pois a arquitetura e a disposição das folhas da aveia permitem maior participação em camadas mais altas na estrutura da vegetação (Lesama \& Moojen, 1999). Isso facilita o pastejo dos pontos de crescimento desta espécie, que, aliado ao seu ciclo curto, promove a emissão de 
perfilhos em número e velocidade insuficientes para recuperação rápida da estrutura da pastagem. O azevém possui desenvolvimento inicial lento, mas supera, em quantidade de forragem, as demais espécies forrageiras até o fim da primavera (Santos et al., 2002), fato confirmado pelos resultados deste experimento.

Houve efeito da interação $(\mathrm{P}<0,05)$ tratamento $\times$ períodos sobre os teores de PB da pastagem (Figura 4). As médias percentuais de $\mathrm{PB}$ da forragem na entrada e saída dos animais dos potreiros diferiram $(\mathrm{P}<0,05)$ entre métodos de estabelecimento, com maiores valores obtidos na pastagem sobre-semeada. $\mathrm{O}$ teor de $\mathrm{PB}$ na entrada dos animais reflete a qualidade da forragem colhida no primeiro dia de pastejo. Como o comportamento se torna mais seletivo à medida que aumenta o número de dias dos animais no piquete, gradualmente a qualidade diminui, o que explica a diferença da qualidade de forragem da entrada e saída dos

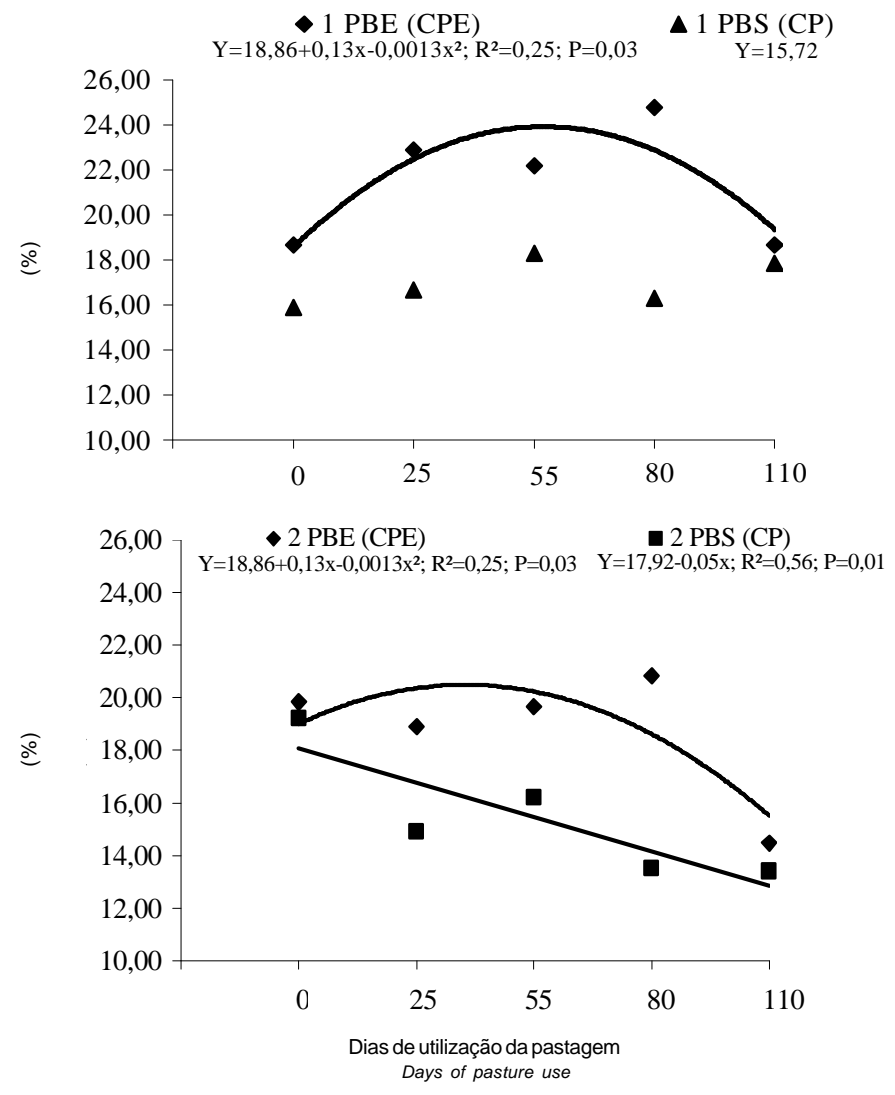

Figura 4 - Teores de PB na entrada (PBE) e saída (PBS) dos animais em pastagens de aveia (A. strigosa Schreb.) e azevém (L. multiflorum Lam.) estabelecidas por sobre-semeadura (1) ou em cultivo estreme (2).

Figure 4 - $\quad C P$ concentration in the pre- (CPE) and post-grazing $(C P)$ forage collected on oats (A. strigosa Schreb.) and ryegrass (L. multiflorum Lam.) pasture established by sodseeding(1) or in extreme tillage (2). animais da pastagem. A concentração de nitrogênio nas forrageiras é maior nas lâminas foliares e o maior teor de PB da pastagem sobre-semeada é explicado pela maior participação de folhas neste tratamento (Tabela 1). Prohmann et al. (2004) encontraram valor médio de 21,8\% PB nas lâminas foliares da mistura de aveia e azevém introduzida em pastagem de coastcross, valores semelhante aos encontrados neste experimento pela simulação de pastejo.

A estrutura da planta modifica-se durante seu ciclo, alterando as proporções entre lâminas foliares e colmos e, conseqüentemente, os nutrientes e os componentes acessíveis ao animal. Pedroso et al. (2004) verificaram teores mais elevados de PB no estádio vegetativo do azevém (em torno de $23,7 \%$ ), diminuindo à medida que as plantas se aproximaram do florescimento.

Houve diferença entre tratamentos $(\mathrm{P}<0,05$; Figura 5) quanto ao teor de FDN na entrada dos animais, que foi
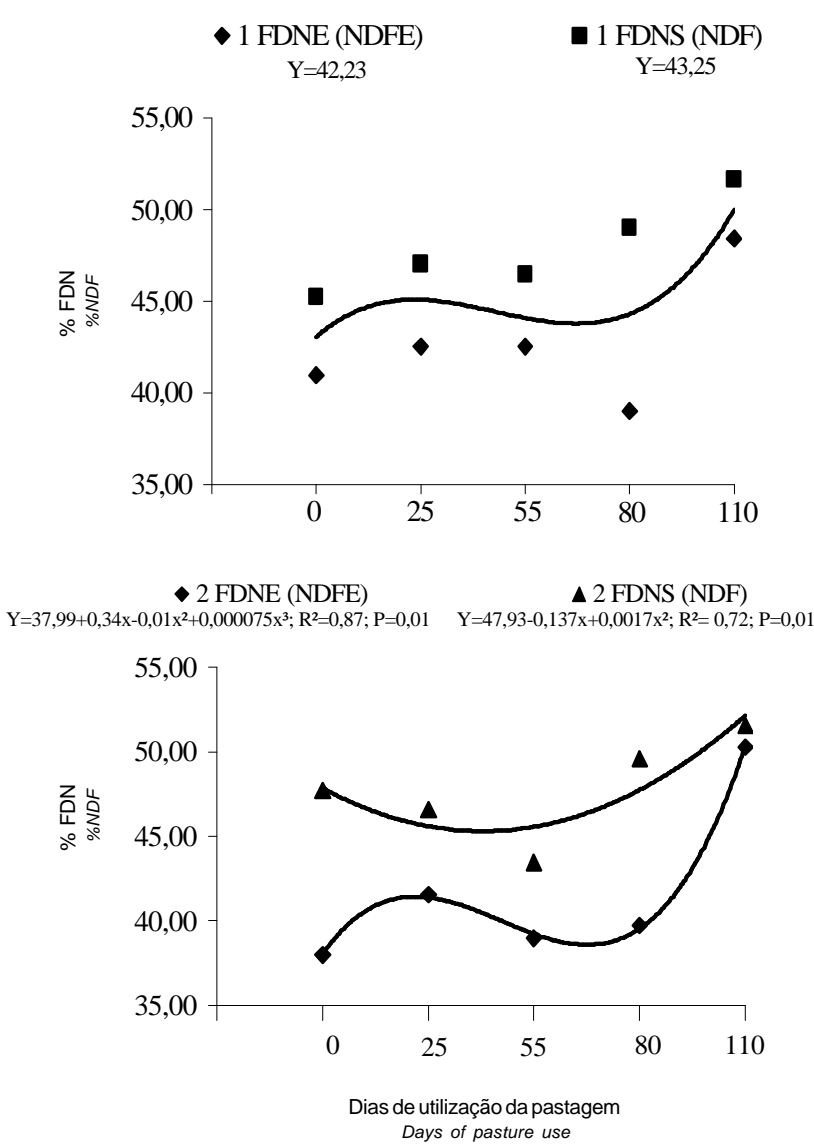

Figura 5 - Teores de FDN na entrada (FDNE) e saída (FDNS) dos animais em pastagens de aveia ( $A$. strigosa) e azevém (L. multiflorum) estabelecidas por sobre-semeadura (1) ou cultivo estreme (2).

Figure 5 - NDF concentration in the pre- (NDFE) and post-grazing (NDF) forage collected on oats (A. strigosa Schreb) and ryegrass (L. multiflorum Lam.) pasture established by sodseeding (1) or in extreme tillage (2). 
maior na pastagem estreme, não havendo diferenças no teor de FDN na forragem por ocasião da saída dos animais.

Os valores médios de FDN foram de $41,7 \%$ em pastagem sobre-semeada e $43,7 \%$ em cultivo estreme. A diferença nos teores de FDN da entrada e saída é explicada pela menor quantidade de lâminas foliares (Tabela 1), pois os colmos possuem maior porcentagem de FDN que as lâminas foliares. Neto et al. (2005) demonstraram que os teores de FDN aumentam à medida que avança o ciclo da pastagem e que este comportamento está associado ao aumento na massa de colmos e à lignificação das paredes celulares nos tecidos. Portanto, os teores de PB mais baixos e de FDN mais elevados na saída dos animais dos piquetes refletem a maior proporção de lâminas foliares na dieta selecionada pelo animal.
A análise de correlação entre as variáveis de produção e qualidade de forragem está expressa na Tabela 2. Altas proporções de lâminas foliares são obtidas em MFE elevada, com maiores teores de PBE, admitindo-se elevada CA. O aumento da CA, no entanto, provoca decréscimos na $\mathrm{OF}$, como pode ser verificado pela associação significativa entre essas variáveis. O avanço do período de utilização da pastagem e sua aproximação da época de florescimento promove alongamento dos entrenós e, conseqüentemente, maior proporção de colmos na MFE. Os colmos possuem maior teor de MS e FDN se comparados às lâminas foliares, o que explica a associação entre a proporção lâminas foliares/ colmos (LF/C) e a massa de forragem da entrada, o resíduo e o teor de FDN, representada pela correlação negativa entre as variáveis.

Tabela 2 - Correlações e níveis de significância entre as variáveis massa de forragem de entrada (MFE), resíduo (RES), carga animal (CA), teores de PB de entrada (PBE) e saída (PBS), teores de FDN de entrada (FDNE) e saída (FDNS), massa de lâminas foliares (MLAM), oferta de forragem (OF) e proporção entre lâminas foliares e colmos (LF/C) de pastagens de aveia (A. strigosa) e azevém (L. multiflorum) estabelecidas por sobre-semeadura ou cultivo estreme

Table 2 - Correlation and significance levels between herbage mass (HM), residual herbage mass (RES), stocking rate (SR), pre-grazing CP (CPE), post-grazing CP (CPS), pre-grazing NDF (NDFE), post-grazing NDF (NDFS), leaf blade biomass (LBB), forage on offer (FO) and proportion of leaf blade and stem (LB/S) of oats (A. strigosa) and ryegrass (L. multiflorum) pasture established by sodseeding or in extreme tillage

\begin{tabular}{|c|c|c|c|c|c|c|c|c|c|c|c|}
\hline $\begin{array}{l}\text { Variável } \\
\text { Item }\end{array}$ & & $\begin{array}{c}\text { MFE } \\
H M\end{array}$ & $\begin{array}{l}\text { RES } \\
\text { RES }\end{array}$ & $\begin{array}{l}\text { CA } \\
S R\end{array}$ & $\begin{array}{l}\text { PBE } \\
C P E\end{array}$ & $\begin{array}{l}\text { PBS } \\
C P S N\end{array}$ & $\begin{array}{c}\text { FDNE } \\
D F E\end{array}$ & $\begin{array}{c}\text { FDNS } \\
N D F S\end{array}$ & $\begin{array}{c}\text { MLAM } \\
\angle B B\end{array}$ & $\begin{array}{l}\mathrm{OF} \\
F O\end{array}$ & $\begin{array}{r}\mathrm{LF} / \mathrm{C} \\
L B / S\end{array}$ \\
\hline MFE & $\mathrm{r}^{1}$ & 1 & & & & & & & & & \\
\hline$H M$ & Prob. $^{2}$ & 0 & & & & & & & & & \\
\hline RES & $r$ & 0,20 & 1 & & & & & & & & \\
\hline$R E S$ & Prob. & 0,40 & 0 & & & & & & & & \\
\hline CA & r. & 0,75 & 0,42 & 1 & & & & & & & \\
\hline$S R$ & Prob & & 0,0001 & 0,06 & 0 & & & & & & \\
\hline PBE & $\mathrm{r}$ & 0,46 & 0,09 & 0,1 & 1 & & & & & & \\
\hline$C P E$ & Prob. & 0,04 & 0,7 & 0,67 & 0 & & & & & & \\
\hline PBS & $\mathrm{r}$ & 0,27 & $-0,16$ & 0,21 & 0,4 & 1 & & & & & \\
\hline$C P S$ & Prob. & 0,23 & 0,48 & 0,35 & 0,07 & 0 & & & & & \\
\hline FDNE & $\mathrm{r}$ & 0,07 & 0,28 & 0,29 & $-0,62$ & $-0,06$ & 1 & & & & \\
\hline$N D F E$ & Prob. & 0,75 & 0,22 & 0,21 & 0,003 & 0,80 & 0 & & & & \\
\hline FDNS & $\mathrm{r}$ & $-0,03$ & $-0,08$ & 0,37 & $-0,27$ & $-0,29$ & 0,55 & 1 & & & \\
\hline$N D F S$ & Prob. & 0,87 & 0,71 & $-0,21$ & 0,24 & 0,20 & 0,01 & 0 & & & \\
\hline MLAM & $\mathrm{r}$ & 0,22 & $-0,47$ & 0,04 & 0,53 & 0,55 & $-0,64$ & $-0,43$ & 1 & & \\
\hline$L B B$ & Prob. & 0,34 & 0,03 & 0,85 & 0,01 & 0,01 & 0,0021 & 0,05 & 0 & & \\
\hline OF & $\mathrm{r}$ & $-0,89$ & 0,09 & 0,0015 & $-0,34$ & $-0,26$ & 0,03 & 0,06 & $-0,37$ & 1 & \\
\hline FO & Prob. & 0,0001 & 0,69 & $-0,66$ & 0,13 & 0,27 & 0,87 & 0,79 & 0,10 & 0 & \\
\hline $\mathrm{LF} / \mathrm{C}$ & r & $-0,48$ & $-0,72$ & 0,0081 & $-0,04$ & 0,10 & $-0,46$ & $-0,04$ & 0,58 & 0,24 & 1 \\
\hline$L B / S$ & Prob. & 0,029 & 0,0003 & $-0,57$ & 0,83 & 0,66 & 0,03 & 0,85 & 0,007 & 0,30 & 0 \\
\hline
\end{tabular}

${ }^{1}$ Coeficiente de correlação; ${ }^{2}$ Probabilidade.

${ }^{1}$ Correlation coefficient; ${ }^{2}$ Probability. 


\section{Conclusões}

A sobre-semeadura afeta a produção total de forragem da aveia, mas não tem efeitos sobre a produção do azevém. A produção de forragem de coastcross, entretanto, complementa a menor disponibilidade da aveia, demonstrando que a introdução de aveia e azevém por sobresemeadura em pastagem de coastcross é uma alternativa viável, pois assegura produção de forragem e carga animal idêntica aos métodos de estabelecimentos convencionais, evitando a ociosidade das áreas ocupadas com pastagens perenes de verão durante a estação fria.

O estabelecimento de aveia e azevém por sobre-semeadura em pastagem de coastcross possibilita a oferta de maior biomassa de lâminas foliares aos animais em pastejo, com conteúdo maior de nitrogênio e menor de FDN.

\section{Literatura Citada}

CAMPBELL, A.G. Grazed pastures parameters. I. Pasture dry matter production and availability in a stocking rate and grazing management experiment with dairy cows. Journal of Agriculture Science, v.67, p.211-216, 1966.

EMPRESA BRASILEIRA DE PESQUISA E AGROPECUÁRIA EMBRAPA. Sistema brasileiro de classificação de solos. Rio de Janeiro: EMBRAPA, 1999. 412p.

EUCLIDES, V.P.B.; MACEDO, M.C.M.; OLIVEIRA, M.P. Avaliação de diferentes métodos para se estimar o valor nutritivo de forragens sob pastejo. Revista Brasileira de Zootecnia, v.21, n.4, p.691-702, 1992.

FREITAS, F.K.; ROCHA, M.G.; RESTLE, J. et al. Suplementação energética na recria de fêmeas de corte em pastagem cultivada de inverno. Revista Brasileira de Zootecnia, v.34, n.4, p.1256-1266, 2005.

FRIZZO, A.; ROCHA, M.G.; RESTLE, J. et al. Efeito de diferentes níveis de suplementação energética no desempenho de bezerras em pastejo. Revista Brasileira de Zootecnia, v.32, n.3, p.643-652, 2003.

GERDES, L.G.; MATTOS, H.B.; WERNER, J. et al. Características do dossel forrageiro e acúmulo de forragem em pastagem irrigada de capim-aruana exclusivo ou sobre-semeado com uma mistura de espécies forrageiras de inverno. Revista Brasileira de Zootecnia, v.34, n.4, p.1088-1097, 2005

LENZI, A. Desempenho animal e produção de forragem em dois sistemas de uso da pastagem: pastejo contínuo \& pastoreio racional voisin. Florianópolis: Universidade Federal de Santa Catarina, 2003. 133p. Dissertação (Mestrado em Agroecossistemas) - Universidade Federal de Santa Catarina, 2003.

LESAMA, M.F.; MOOJEN, E.L. Produção animal em gramíneas de estação fria com fertilização nitrogenada ou associadas com leguminosa, com ou sem fertilização nitrogenada. Ciência Rural, v.29, n.1, p.123-128, 1999
MELO, J.S. Produção de forragens para o gado leiteiro, no sistema plantio direto. In: KOCHHANN, R.A.; TOMM, G.O.; FONTANELLI, R.S. (Eds.) Sistemas de produção de leite baseados em pastagens sob plantio direto. Passo Fundo: Embrapa Trigo/ Juiz de Fora: Embrapa Gado de Leite/ Bagé: Embrapa Pecuária Sul/ Montevideo: Procisur, 2000. p.215-228.

PEDROSO, C.E.S; MEDEIROS, R.B.; SILVA, M.A. et al. Produção de ovinos em gestação e lactação sob pastejo em diferentes estádios fenológicos de azevém anual. Revista Brasileira de Zootecnia, v.33, n.5, p.1345-1350, 2004

PENATI, M.A. Estudo do desempenho animal e produção do capim Tanzânia (Panicum maximum Jacq.) em um sistema rotacionado de pastejo sob irrigação em três níveis de resíduo pós pastejo. Piracicaba: Escola Superior de Agricultura "Luiz de Queiroz", 2002. 117p. Tese (Doutorado em Agronomia) - Escola Superior de Agricultura "Luiz de Queiroz", 2002.

PILLAR, V.D.P. Multivariate exploratory analysis and randomization testing with MULTIV. Coenoses, v.12, p.145-148, 1997.

PROHMANN, P.E.F; BRANCO, A.F.; CECATO, U. et al. Suplementação de bovinos em pastagem de coastcross (Cynodon dactylon (L.) Pers.) no inverno. Revista Brasileira de Zootecnia, v.33, n.4, p.801-810, 2004.

RIZO, L.M.; MOOJEN, E.L.; QUADROS, F.L.F. et al. Desempenho de pastagem nativa e pastagem sobre-semeada com forrageiras hibernais com e sem glifosato. Ciência Rural, v.34, n.6, p.1921-1926, 2004.

ROCHA, M.G.; MONTAGNER, D.B.; SANTOS, D.T. et al. Parâmetros produtivos de uma pastagem temperada submetida a alternativas de utilização. Revista Brasileira de Zootecnia, v.33, n.6, p.1386-1395, 2004

ROCHA, M.G.; RESTLE, J.; FRIZZO, A. et al. Alternativas de utilização da pastagem hibernal para a recria de bezerras de corte. Revista Brasileira de Zootecnia, v.32, n.2, p.383392,2003

ROSO C.; RESTLE J.; SOARES A.B. et al. Produção e qualidade de forragem da mistura de gramíneas anuais de estação fria sob pastejo contínuo. Revista Brasileira de Zootecnia, v.28, n.3, p.459-467, 1999 .

ROSO, C.; RESTLE, J.; SOARES, A.B. et al. Aveia-preta, triticale e centeio em mistura com azevém. I. Dinâmica, produção e qualidade de forragem. Revista Brasileira de Zootecnia, v.29, n.1, p.75-84, 2000 .

SANTOS, H.P.; FONTANELI, R.S.; BAIER, A.C. et al. Principais forrageiras para integração lavoura-pecuária, sob plantio direto, nas Regióes Planalto e Missões do Rio Grande do Sul. Passo Fundo: Embrapa Trigo, 2002. 142p.

STATISTICAL ANALYSIS SYSTEM - SAS. SAS/STAT software: changes and enhancements through release 6.12. Cary: 1997. $1167 \mathrm{p}$

SILVA, A.C.F.; QUADROS, F.L.F.; TREVISAN, N.B. et al. Recria de terneiros de corte em pastagem de estação fria sob níveis de biomassa de folhas verdes: economicidade e eficiência alimentar. Ciência Rural, v.34, n.6, p.1903-1907, 2004.

WILM, H.G.; COSTELO, D.F.; KLIPPLE, G.E. Estimating forage yield by the double sampling method. Journal of the American Society for Agriculture, v.36, n.1, p.194-203, 1944.

Recebido: 03/11/05 Aprovado: 28/08/06 